\title{
Sex Ratio, Habitat Selection and Foraging Behavior of Mandarin Duck in Water Systems of Poyang Lake, China
}

\author{
He Wenyun, Zhi Yijin and Shao Mingqin* \\ College of Life Science, Jiangxi Normal University, Nanchang, Jiangxi, 330022, China
}

\begin{abstract}
A B S T RA C T
From February to March 2017, November 2017 to March 2018 and November 2018 to March 2019 we used the point count method to survey the sex ratio, habitat selection and foraging behavior of Mandarin duck (Aix galericulata) in water systems (Raohe River, Ganjiang River and Xiuhe River) of Poyang Lake, Jiangxi Province, China. We recorded 162 individuals and determined 141 by gender: the sex ratio was 1.07. There was no significant male bias $(n=141, p=0.210)$. Habitat selection results indicated that Mandarin duck tended to choose habitat with vegetation cover $(2.40 \pm 0.84)$ on riverbanks, with shoal proportions of $8.00 \pm 6.00 \%$, water velocity of $0.16 \pm 0.12 \mathrm{~m} / \mathrm{s}$ and wider river widths of $190.90 \pm 113.80$ $\mathrm{m}$. The foraging habitats were far from sources of disturbance such as mine factory $(2.70 \pm 0.48)$, village $(286.10 \pm 168.97 \mathrm{~m})$ and road $(114.50 \pm 105.01 \mathrm{~m})$. Our study showed that riverbank vegetation $(Z=-$ 2.614, $P=0.009)$, distance to village $(Z=-2.859, P=0.004)$ and $\operatorname{road}(Z=-2.085, P=0.037)$ in the foraging habitats were significantly higher than in control plots, indicating that Mandarin duck clearly preferred habitats with higher vegetation cover remote from both village and road. Principal component analysis indicated that water flow speed, distance to village, river width, vegetation cover, distance to mine factory and shoal proportion were the main factors for habitat selection. The results suggested that safety was the primary factor in habitat selection. The main foraging method was up-ending (61.54\%); the duration of each up-ending foraging behavior was $1.92 \pm 0.83 \mathrm{~s}$ and foraging frequency was $14.67 \pm 4.43$ times $/ \mathrm{min}$. This foraging strategy may be determined by food distribution and morphological structure.
\end{abstract}

Article Information
Received 13 November 2019
Revised 12 February 2020
Accepted 05 March 2020
Available online 11 September 2020
Authors' Contribution
SMQ designed and revised the paper.
HWY, ZYJ and SMQ collected and
analyzed the data. HWY wrote the
paper.
Key words
Water system of Poyang Lake,
Mandarin duck, Aix galericulata,
Habitat selection, Foraging behavior

\section{INTRODUCTION}

A nseriformes, an important ecological group of water birds, are very sensitive to wetland changes and can act as an indicator species of wetland environmental quality. Previous studies of Anseriformes include population size and distribution (Fang et al., 2019a), foraging behaviors and foraging habits (Hill and Eills, 1984; Liu, 2011; Cervencl and Fernandez, 2012), habitat selection (Nummi and Pöysä, 1995; Sun et al., 2018), overwintering ecology (Yang, 2013) and breeding ecology (Wang et al., 2019). Factors influencing habitat selection of Anseriformes include topography and geomorphology (Nummi and Pöysä, 1995), vegetation (Sebastián et al., 2013), disturbance factors (Sun et al., 2018) and shelter factors (Fan et al., 2017). Habitat selection may change with season (Sebastián et al., 2013). The foraging behavior of Anseriformes is affected by factors such as food abundance (Cervencl and Fernandez, 2012), age (Yang, 2013), gender (Hill and Eills, 1984) and water depth (Yang, 2013). Studies of Anseriform habitat selection and

\footnotetext{
* Corresponding author: 1048362673@qq.com 0030-9923/2020/0006-2251 \$ 9.00/0 Copyright 2020 Zoological Society of Pakistan
}

foraging behavior are very significant in habitat management and bird conservation.

The Mandarin duck (Aix galericulata) belongs to the Anatidae family of Anseriformes, and its global population is estimated as 65,000-66,000 individuals. Mandarin duck is listed in the second category of the nationally protected wild species in China. It breeds mainly in eastern Russia, Japan, Korea and northern China, and overwinter mainly in Burma, northeastern India and the Yangtze river in China. It occasionally breeds in the wintering areas of Fujian, Yunnan and Guizhou, China (Fang et al., 2019a). Studies of Mandarin duck include population size and distribution (Fang et al., 2019a), behaviors (Fang et al., 2019b) and breeding ecology (Jin et al., 2010; You et al., 2017). Behaviors in the overwintering stage have been studied (Yang, 2013), but there is no research into the habitat selection and foraging behavior of Mandarin duck in the water system of Poyang Lake. Thus, the objective of our study was as follows: (1) to establish the factors influencing habitat selection of Mandarin duck; and (2) to understand its foraging behavior strategy. The results will provide basic data on habitat use and foraging behavior strategy of Mandarin duck in the water system of Poyang Lake, and provide a scientific basis for habitat management and future protection of the species. 


\section{MATERIALS AND METHODS}

\section{Study area}

Poyang Lake $\left(115^{\circ} 49^{\prime} \mathrm{E}-116^{\circ} 46^{\prime} \mathrm{E}, 28^{\circ} 11^{\prime} \mathrm{N}-29^{\circ} 51^{\prime}\right.$ $\mathrm{N})$, located in the North Jiangxi Province, is the largest freshwater lake in China. Five river systems (Xiuhe River, Ganjiang River, Fuhe River, Xinjiang River, Raohe River) and their tributaries, combined with Poyang Lake, form a radial water system known as the water system of Poyang Lake (Yu et al., 2011). The basin area of the water system of Poyang Lake is $162,200 \mathrm{~km}^{2}$, equivalent to $97 \%$ of the land area of Jiangxi Province (Zhou et al., 2018). The study area has a subtropical monsoon climate, with an average annual temperature of $16.3-19.5^{\circ} \mathrm{C}$; frost-free periods range from 240 to 307 days; and the duration of daily temperature stability over $10^{\circ} \mathrm{C}$ is $240-270$ days. The basin has typical subtropical forest plant communities and abundant bird resources. This research area located in some river sections in Ji'an, Wuyuan, Xiushui and Jingdezhen. The vegetation was dominated by bamboo forests, coniferous forests, and by mixed broadleaf and coniferous forests. The water was clear and had a relative large velocity.

\section{Bird surveys}

From February to March 2017, November 2017 to March 2018, and November 2018 to March 2019, we used a point count method in the river sections of the Raohe River (Jingdezhen and Wuyuan), Ganjiang River (Ji'an) and Xiuhe River (Jing'an) in the water system of Poyang Lake. Observations were made using binoculars $(\times 8)$ and monoculars $(\times 20-60)$, and the number and gender of Mandarin duck were then recorded. A total of 19 sample points (10 habitat points and 9 control points) was selected in the survey, along a total length of approximately $141 \mathrm{~km}$. Among them, 10 samples $(5$ habitat points and 5 control points) were selected for the Raohe River, with a length of approximately $70 \mathrm{~km}$; 6 samples ( 3 habitat points and 3 control points) were selected for the Ganjiang River section, with a length of approximately $35 \mathrm{~km}$; and 3 samples ( 2 habitat points and 1 control points) were selected for the Xiuhe River section, with a length of approximately $36 \mathrm{~km}$ (Fig. 1). After we found foraging Mandarin duck, seven habitat parameters were recorded (Table I). Within the range of $2-5 \mathrm{~km}$ from the foraging habitat, we also selected the regions where Mandarin duck have never been found in recent years, as control plots, and recorded the corresponding data. The foraging pattern, behavior duration of each foraging event, foraging times and foraging interval of Mandarin duck were recorded by animals focus sampling. The foraging patterns of Mandarin duck were divided into
(1) feeding from the water surface; (2) dipping with only head submersed; (3) dipping with head and neck submersed; and (4) up-ending (tipping-up/tilting, foot stamping) (Tatu et al., 2007).

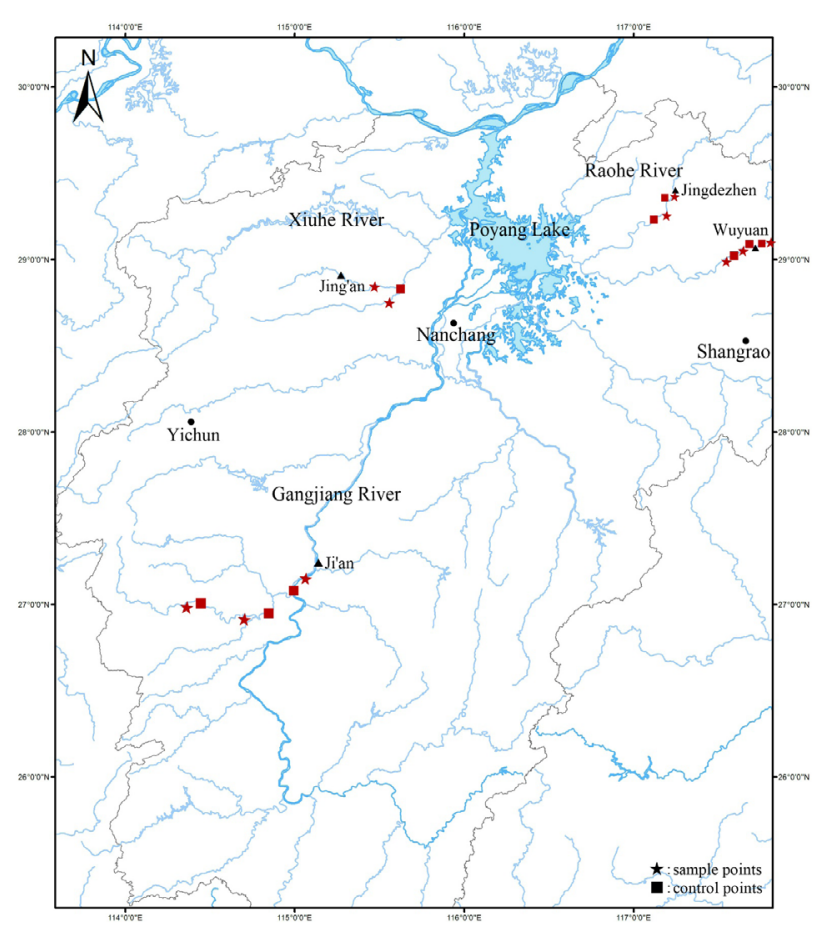

Fig. 1. Locations of the survey areas in three rivers of Poyang Lake.

\section{Data analysis}

A binomial distribution test was used to examine if sex ratio $\left(\delta^{\lambda}:\right.$ ) $)$ of Mandarin duck significantly showed. If the data fitted normal distribution, we compared differences in habitat factors between habitats and control plots using the independent sample t-test. If the data did not fit, the MannWhitney U test was used. Factors determining habitat selection of Mandarin duck were identified using principal component analysis (PCA). Values were expressed as means \pm standard deviation at the $\alpha=0.05$ significance level. Statistical analyses were completed using Excel 2016 and SPSS 21.0.

\section{RESULTS}

A total of 162 Mandarin duck was recorded in this survey, with a sex ratio of $1.07(n=141)$. Sex ratio was 0.79 $(n=73)$ in Wuyuan; $1.50(n=50)$ in $\mathrm{Ji}$ 'an; and $1.25(n=18)$ in Jing'an. The binomial distribution test indicated that there was no significant bias in the three regions or in the overall sex ratio (Table II). 
Table I. Habitat parameters and measurement methods.

\begin{tabular}{ll}
\hline Habitat parameters & Measurement \\
\hline Water flow speed $(\mathrm{m} / \mathrm{s})$ & $\begin{array}{l}\text { Measured by stopwatch, the time for a floating object to move 1 m was recorded (mean of } 5 \text { consecutive } \\
\text { recordings). }\end{array}$ \\
$\begin{array}{l}\text { River width }(\mathrm{m}) \\
\text { Vegetation cover of river- }\end{array}$ & $\begin{array}{l}\text { Vegetation cover of riverbank within } 20 \times 20 \mathrm{~m} \text { plots centered on a habitat of Mandarin duck, estimated } \\
\text { by eye. We divided vegetation cover into three ranks: } 1(<10 \%) ; 2(10 \%-20 \%) ; \text { and } 3(>20 \%) .\end{array}$ \\
bank & $\begin{array}{l}\text { Shoal proportion within } 20 \times 20 \mathrm{~m} \text { plots centered on the Mandarin duck, measured by eye. } \\
\text { Shoal proportion }(\%)\end{array}$ \\
Distance to mine factory & $\begin{array}{l}\text { Distance to the nearest mine factory from the watercourse center. We divided distances into three ranks: } \\
1(<250 \mathrm{~m}) ; 2(250-500 \mathrm{~m}) ; \text { and } 3(>500 \mathrm{~m}) .\end{array}$ \\
$\begin{array}{l}\text { Distance to village }(\mathrm{m}) \\
\text { Distance to road }(\mathrm{m})\end{array}$ & $\begin{array}{l}\text { Distance to the nearest village from the watercourse center. } \\
\text { Distance to the nearest road from the watercourse center. }\end{array}$ \\
\hline
\end{tabular}

Table II. Population and sex ratio of Mandarin duck in Poyang Lake water system.

\begin{tabular}{|c|c|c|c|c|c|c|}
\hline Survey site & Population & Male & Female & Sex ratio & $\mathbf{n}$ & $\mathbf{p}$ \\
\hline Wuyuan & 88 & 33 & 40 & 0.83 & 73 & 0.483 \\
\hline $\mathrm{Ji}$ 'an & 52 & 30 & 20 & 1.50 & 50 & 0.203 \\
\hline Jing 'an & 18 & 10 & 8 & 1.25 & 18 & 0.815 \\
\hline Jingdezhen & 4 & - & - & 0.00 & - & - \\
\hline Total & 162 & 73 & 68 & 1.07 & 141 & 0.210 \\
\hline
\end{tabular}

Note: Some individuals did not distinguish gender.

\section{Habitat selection}

Mann-Whitney U tests showed that vegetation cover of two banks $(Z=-2.614, P=0.009)$, and the distance to village $(Z=-2.859, P=0.004)$ and road $(Z=-2.085, P=0.037)$ were significantly higher than in the control plots, and there were no significant differences in other parameters (Table III).

The first two components met the criterion of eigenvalue $>1$ and the third $(0.981)$ was close to 1 ; together they explained $81.26 \%$ of the variance in habitats by using the PCA method. This result indicated that the first three principal components contained most messages of habitat parameters and may reflect the habitat selection of Mandarin duck (Table IV). The contribution rate of the first principal component was $38.28 \%$, and the absolute value of factor load mainly included water flow speed and distance to village. These factors were related to water environment and distance to disturbance. The contribution rate of the second principal component was $28.95 \%$. The factors with larger absolute value of factor load included river width, vegetation cover of riverbank and distance to mine factory, and these were related to shelter. The third principal component contribution rate was $14.02 \%$, and the shallow shoal proportion had the highest absolute value of factor loading (Tables IV and V). Comprehensive analysis of the above factors indicated that the safety factors (shelter and disturbance) were the most important in determining habitat selection by the Mandarin duck.

Table III. Comparison of habitat parameters between foraging habitats and control points for Mandarin duck.

\begin{tabular}{|c|c|c|c|c|c|c|}
\hline \multirow[t]{2}{*}{ Parameters } & \multicolumn{2}{|c|}{ Habitats $(n=10)$} & \multicolumn{2}{|c|}{ Control plots $(n=9)$} & \multirow[t]{2}{*}{$\mathbf{Z}$} & \multirow[t]{2}{*}{$\mathbf{P}$} \\
\hline & Mean & SD & Mean & SD & & \\
\hline Water flow speed (m/s) & 0.16 & 0.12 & 0.09 & 0.09 & -1.239 & 0.215 \\
\hline River width (m) & 190.90 & 113.80 & 142.11 & 70.67 & -0.939 & 0.348 \\
\hline Vegetation cover of riverbank & 2.40 & 0.84 & 1.33 & 0.50 & -2.614 & $0.009^{*}$ \\
\hline Shoal proportion (\%) & 8.00 & 6.00 & 5.00 & 7.00 & -1.281 & 0.200 \\
\hline Distance to mine factory & 2.70 & 0.48 & 2.78 & 0.67 & -0.804 & 0.421 \\
\hline Distance to village (m) & 286.10 & 168.97 & 75.44 & 72.94 & -2.859 & $0.004^{*}$ \\
\hline Distance to road (m) & 114.50 & 105.01 & 42.67 & 61.70 & -2.085 & $0.037^{*}$ \\
\hline
\end{tabular}

Note: * There are significant differences between foraging habitat and control plots. 
Table IV. Eigenvalues and contribution rates of habitat selection factors of Mandarin duck $(n=10)$.

\begin{tabular}{|c|c|c|c|}
\hline $\begin{array}{l}\text { Principal } \\
\text { component }\end{array}$ & $\begin{array}{l}\text { Eigenval- } \\
\text { ue }\end{array}$ & $\begin{array}{l}\text { Percent of total } \\
\text { variance }(\%)\end{array}$ & $\begin{array}{l}\text { Percent of cumula- } \\
\text { tive variance }(\%)\end{array}$ \\
\hline 1 & 2.680 & 38.28 & 38.28 \\
\hline 2 & 2.027 & 28.95 & 67.24 \\
\hline 3 & 0.981 & 14.02 & 81.26 \\
\hline 4 & 0.668 & 9.55 & 90.80 \\
\hline 5 & 0.413 & 5.90 & 96.71 \\
\hline 6 & 0.185 & 2.64 & 99.35 \\
\hline 7 & 0.046 & 0.66 & 100.00 \\
\hline
\end{tabular}

Table V. Correlation of habitat variables with the first three principal components derived from habitat selection of Mandarin duck $(n=10)$.

\begin{tabular}{llll}
\hline Habitat variables & \multicolumn{3}{c}{ Principal components } \\
\cline { 2 - 4 } & $\mathbf{1}$ & $\mathbf{2}$ & $\mathbf{3}$ \\
\hline Water flow speed (m/s) & -0.956 & 0.111 & 0.141 \\
River width (m) & -0.117 & -0.830 & -0.082 \\
Vegetation cover of riverbank & 0.237 & 0.786 & 0.364 \\
Shoal proportion (\%) & -0.049 & 0.081 & 0.949 \\
Distance to mine factory & -0.407 & 0.760 & -0.116 \\
Distance to village (m) & 0.922 & 0.160 & 0.029 \\
Distance to road (m) & 0.442 & -0.517 & -0.468 \\
\hline
\end{tabular}

\section{Foraging behavior}

The foraging patterns of Mandarin duck were mainly up-ending (61.54\%), followed by dipping with head and neck submersed $(31.25 \%)$, feeding from the water surface (11.54\%) and dipping with only head submersed (7.69\%). The duration of each up-ending foraging behavior was $1.92 \pm 0.83 \mathrm{~s}$, the foraging frequency was $14.67 \pm 4.43 \mathrm{times} /$ min and the foraging interval was $5.83 \pm 3.19$ seconds/time.

\section{DISCUSSION}

\section{Sex ratio of Mandarin ducks}

Donald (2007) indicated that, among 22 species of Anseriformes, the sex ratios of 14 species are male biased and that 8 species are balanced (Donald, 2007). The sex ratios of Common Pochard Aythya ferina and Baer's Pochard A. fuligula in Northern Ireland are 2.57 and 1.94, respectively (Evans and Day, 2001), both of which indicate obvious male skewness. The sex ratios of Common Teal Anas crecca and Falcated Teal A. falcata in Poyang Lake,
China, are 1.54 and 1.09 , respectively. Another study in Poyang Lake indicates that Scaly-sided Merganser Mergus squamatus has a sex ratio of 0.66 , indicating female bias; this is related to female records, including a number of sub-adults. The sex ratio of Mandarin duck in Taiwan (2.10) (Sun et al., 2011) and northeastern Germany (1.86) (Bellebaum and Mädlow, 2015) indicate male bias. The sex ratio of Mandarin duck in our study was balanced (1.07), and similar to that of Guizhou province (1.14) (Fang et al., 2019b). The possible explanations of different sex ratios include: (1) female and male ducks had different mortality in different regions; (2) males and females arrived in breeding or wintering areas at different times; and (3) males and females did not choose exactly the same habitats.

\section{Habitat selection}

The results indicated that, in some river sections, Mandarin duck tended to choose a river with a proper velocity, wider river width, and had higher vegetation cover and shallow banks. They selected foraging habitats far away from disturbance (mine factory, village and road). The greater distance from village and road effectively reduced the interference of human activities, improved the shelter of habitat and guaranteed safety. In addition, moderate water flow can purify water, maintain a good water environment, guarantee the quality of the habitat and provide food. However, water flow that was too fast was not a suitable habitat for Mandarin duck because the turbulence might cause them to consume too much energy when foraging. The wider channels and different shoal size slowed down water speeds. Mandarin duck avoided areas that were too close to the mine factory, because they were easily frightened by the running of machinery and vehicles, and this affected their daily activities.

Food, water and shelter are three of the main factors determining habitat selection by wildlife, and human disturbance has a serious impact on the concealment of habitats (Fleskes et al., 2016). PCA results showed that the primary factor influencing Mandarin duck habitat choice was safety. Safety when foraging and resting was an important factor in Mandarin duck survival during the winter period. They were likely to select habitat that had further distance to village, mine factory, road and higher vegetation cover. In this way, they could avoid the interference of human activities and other animals, and gain more safety habitat. This is consistent with the results of Sun et al. (2018), who found that the primary factor affecting night and foraging habitat selection of the Whooper Swan Cygnus cygnus is safety (distance to disturbance sources, height of vegetation). Disturbance is the most important factor in foraging habitat selection of 
the Bar-headed Goose Anser indicus (Yang et al., 2013). Mandarin duck winter activities, such as foraging and resting, are inseparable from the water environment. They have certain water quality requirements, and our PCA results indicated that a suitable water environment was also an essential element of Mandarin duck habitats.

\section{Foraging behavior}

Up-ending foraging was the main foraging strategy adopted by Mandarin duck in this study. When using upending, they entered the water to approximately $1 / 4-3 / 4$ of their body length and foraged at a depth of approximately $15.6-42.5 \mathrm{~cm}$ (Zhang, 2001). This indicates that Mandarin duck can feed on aquatic plants at some depth. This differs from the Tundra Swan C. columbianus in the lotus pond of Poyang Lake, which mainly forages from the water surface and dips with head and neck submersed. The water depth in the foraging area is $8.5-10.5 \mathrm{~cm}$ and $27.5-33.75$ $\mathrm{cm}$. The Swan Goose A. cygnoid mainly forages from the water surface and sediment at a water depth of 7.5-9.9 cm (Zhang et al., 2019). These differences mainly relate to variations in food distribution and the shape of water birds. The Mandarin duck is a medium-sized water bird and can feed on aquatic plants, small fish and shrimps by up-ending feeding (Jiao et al., 2012). However, Tundra Swan and Swan Goose are larger, and mainly feed on plant tubers, roots and zooplankton. The duration of each up-ending foraging event of Mandarin duck (1.92 s) is less than that of Tundra Swan and Swan Goose in the lotus pond (3.92 s and $3.75 \mathrm{~s}$, respectively). The foraging frequency (14.67 times/ min) are greater than those of Tundra Swan and Swan Goose (7.18 times/min and 7.37 times/min, respectively) (Zhang et al., 2019). The possible reason for these differences is that Mandarin duck can find and access its small food items easily, so they had greater foraging frequency. Tundra Swan and Swan Goose lived in shallow lotus ponds and had, with difficulty, to dig for (and then clean) their food. The foraging behavior of Mandarin duck recorded in our study only represented a small sample size. The foraging strategy and influencing factors of Mandarin duck in the water system of Poyang Lake need to be studied further.

\section{ACKNOWLEDGEMENT}

We thank Liwen Bianji, Edanz Editing China (www. liwenbianji.cn/ac), for editing the English text of a draft of this manuscript. Funding for this project was provided by Chinese Natural Sciences Fund (31860611, YC2019-S120, 31560597).

\section{Statement of conflict of interest}

The authors have declared no conflict of interest.

\section{REFERENCES}

Bellebaum, J. and Mädlow, W., 2015. Survival explains sex ratio in an introduced Mandarin duck Aix galericulata population. Ardea, 103: 183-187. https://doi.org/10.5253/arde.v103i2.a7

Cervencl, A. and Fernandez, S.A., 2012. Winter distribution of Greater Scaup Aythya marila in relation to available food resources. J. Sea Res., 73: 41-48. https://doi.org/10.1016/j.seares.2012.06.006

Donald, P.F., 2007. Adult sex ratios in wild bird populations. Ibis, 149: 671-692. https://doi. org/10.1111/j.1474-919X.2007.00724.x

Evans, D.M. and Day, K.R., 2001. Migration patterns and sex ratios of diving ducks wintering in Northern Ireland with specific reference to Lough Neagh. Ring. Migr., 20: 358-363. https://doi.org/10.1080/ 03078698.2001 .9674263

Fan, P.L., Song, C.Q., Li, C.X., Wang, M., Zhang, S., Zhang, Y.T., Qi, Y.P., Chen, X.L., Wang, Y.F. and Wang, H.X., 2017. Nest-site selection of mallard (Anas platyrhynchos) in Daqing Longfeng Wetland. Chinese J. Ecol., 36: 2232-2236.

Fang, Z.Y., Hu, C.S., Ran, J.C. and Xu. G.H., 2019a. Population distribution, research status and prospects of Aix galericulata in China. Wetl. Sci. Manage., 15: 68-72.

Fang, Z.Y., Hu, C.S., Ran, J.C., Xu, G.H. and Wang, C., 2019b. Quantity, distribution and daily behavior of wintering Aix galericulata in Shiqian Mandarin duck Lake National Wetland Park, Guizhou Province. Sichuan J. Zool., 38: 227-234.

Fleskes, J.P., Mauser, D.M., Yee, J.L., Blehert, D.S. and Yarris, G.S., 2016. Flightless and post-molt survival and movements of female mallards molting in Klamath basin. Waterbirds, 33: 208-220. https:// doi.org/10.1675/063.033.0209

Hill, D.A. and Ellis, N., 1984. Survival and age related changes in the foraging behaviour and time budget of Tufted ducklings Aythya fuligula. Ibis, 126: 544550. https://doi.org/10.1111/j.1474-919X.1984. tb02079.x

Jiao, Z.X., Gao, Y.J., Zhang, J.H., Liu, S.X. and Liu, J.Q., 2012. Initial exploration of overwintering Mandarin duck habitat selection along the valley of Qinggan River of three Gorges Area. Sichuan J. Zool., 31: 647-649+654.

Jin, Z.M., Yang, C.W., Liu, Z., Jin, J.L. and Li, N., 2010. A study on the breeding biology of Aix galericulata in Mudangfeng Nature Reserve in Heilongjiang. Sichuan J. Zool., 29: 489-491.

Liu, J., 2011. Diet and activities of wintering Tundra 
bean geese Anser fabalis serrirostris at Shengjin Lake, NNR, Anhui province. University of Science and Technology of China.

Nummi, P. and Pöysä, H., 1995. Habitat use by differentaged duck broods and juvenile ducks. Wildl. Biol., 1: 181-187. https://doi.org/10.2981/wlb.1995.017

Sebastián-González, E., Fuentes, C., Ferrández, M., Echevarrías, J.L. and Green, A.J., 2013. Habitat selection of marbled teal and white-headed duck during the breeding and wintering seasons in southeastern Spain. Bird Conserve. Int., 23: 344-359. https://doi.org/10.1017/S0959270912000305

Sun, H., Yu, H.L., Li, Y.F., Ru, W.D., Gao, R.Y., Zhang, C., Zhang, Y.Q. and Hong, J.M., 2018. Habitat selection for the wintering of whooper swan in Sanmenxia. Wetl. Sci. Manage., 14: 50-53.

Sun, Y.H., Bridgman, C.L., Wu, H.L., Lee, C.F., Liu, M., Chiang, P.J. and Chen, C.C., 2011. Sex ratio and survival of Mandarin ducks in the Tachia River of central Taiwan. Waterbirds, 34: 509-513. https:// doi.org/10.1675/063.034.0415

Tatu, K.S., Anderson, J.T., Hindman, L.J. and Seidel, G., 2007. Diurnal foraging activities of mute swans in Chesapeake Bay, Maryland. Waterbirds, 30: 121-128. https://doi.org/10.1675/15244695(2007)030[0121:DFAOMS]2.0.CO;2

Wang, X.F., Yan, J., Wei, B. and Tan, J., 2019. Reproduction of Baer's Pochard (Aythya baeri) in Huangpi District, Wuhan City. Chinese J. Wildl., 40:190-195.
Yang, E.Y., 2013. A study on wintering behavior of Tundra swans (Cygnus columbianus) at the lakes in the Yangtze River floodplain in Anhui Province. Anhui University.

Yang, Y.F., Zhang, G.G., Lu, J., Liu, L. and Li, Z.J., 2013. Foraging habitat selection of bar-headed goose in winter at Caohai National Reserve in Guizhou. Scient. Silv. Sin., 49: 176-180.

You, Y.Y., Lu, Y.P., Cao, Y.N., Du, Y., Wang, W., Liu, X.F., Jia, T., Cao, C.L. and Zhang, J.G., 2017. Mandarin ducks nest site selection and influence on the reproductive parameter in the city park. $J$. Northeast Norm. Univ. (Nat. Sci. Ed.), 49: 109-113.

Yu, J.X., Zheng, B.F., Liu, Y.F., Liu, Y.F. and Liu, C.L., 2011. Evaluation of soil loss and transportation load of adsorption N and P in Poyang Lake watershed. Acta Ecol. Sin., 31: 3980-3989.

Zhang, C.M., Zhi, Y.J., Lu, P., Shao, M.Q. and Dai, N.H., 2019. Energy expenditure and foraging behavior of wintering Tundra Swan and Swan Goose in a lotus pond reclamation area in Poyang Lake. Chinese $J$. Ecol., 38:785-790.

Zhang, Z.J., 2001. The birds annals of China. Jilin Scientific and Technological Press, Changchun.

Zhou, Y.X., Li, Y.K., Shan, J.H., Tu, X.B., Wei, Z.H., Shao, R.Q. and Zhang, N., 2018. The species diversity of water Birdsin the five river-catchment of Poyang Lake. J. Jiangxi Normal Univ. (Nat. Sci. Ed.), 42: 571-577. 